\title{
Las preguntas confirmatorias como indicadoras de posicionamiento intersubjetivo
}

\author{
Tag questions as intersubjective stance markers

\section{María Leticia Móccero} \\ Universidad Nacional de La Plata, La Plata, Argentina. \\ Correo electrónico: mmoccero@huma.fahce.unlp.edu.ar
}

En este trabajo abordamos el análisis de las preguntas confirmatorias ‘¿no?’ y ‘ ¿sí?’como marcadores de posicionamiento intersubjetivo en la conversación informal. Entendemos que los elementos estudiados pueden tener distintas funciones y contribuir a que el hablante adopte un determinado posicionamiento según sus propósitos comunicativos. Desde el marco de la Teoría de la Valoración realizamos un estudio cualitativo de la muestra con el propósito de clasificar las preguntas confirmatorias presentes en los textos según su función, establecer si contribuyen a marcar un determinado posicionamiento intersubjetivo y buscar similitudes y diferencias en la forma en que dichas preguntas funcionan en los diversos tipos de fragmentos incrustados en las conversaciones.

Palabras clave: valoración, posicionamiento, preguntas confirmatorias, fragmentos genéricos.

In this paper we analyse tag questions yes? and no? as Intersubjective Stance markers in casual conversation. We consider that the elements studied can have different functions in discourse, and can contribute to the adoption of a certain intersubjective stance, according to the speaker's communicative needs. The theoretical framework adopted for the research is appraisal theory. We carry out a qualitative analysis of the corpus with the purpose of classifying the confirming tags occurring in the corpus, establishing whether they contribute to the adoption of a particular Intersubjective Stance, finding similarities and differences in the way these questions function in the different generic fragments embedded in the conversations.

Key words: appraisal, stance, confirming tags, generic fragments.

\section{INTRODUCCIÓN}

En este estudio -parte de una investigación más amplia sobre los géneros en la interacción verbal que se está llevando a cabo en la Universidad Nacional de La Plata-continuamos con el estudio del posicionamiento intersubjetivo (Intersubjective Stance) (White 2003, Martin y White 2005) comenzado en trabajos anteriores (Móccero 2005, 2007 y 2008). Abordamos el análisis de las preguntas confirmatorias ¿no? y ¿sí? como marcadores de posicionamiento en conversaciones informales. 
El corpus está formado por 24 conversaciones espontáneas diádicas y poliádicas (aproximadamente 8 horas de grabación) entre estudiantes universitarios argentinos de ambos sexos, cuyas edades oscilan entre los 18 y los 28 años de edad. Los participantes -que en algunos casos son amigos y en otros se encuentran por primera vez- pertenecen a distintas carreras y facultades, y proceden de distintos puntos del país.

Para la recolección del corpus se solicitó a los sujetos de la investigación que se reunieran en un lugar ajeno a la Universidad e interactuaran durante un mínimo de 20 minutos sobre temas de su interés. No se sugirió temario alguno. Dichas conversaciones fueron grabadas en audio, sin la presencia del investigador, y luego se efectuó la transcripción de las mismas.

Para la realización de este trabajo efectuamos en primer lugar un microanálisis cualitativo de la muestra con el propósito de clasificar las preguntas confirmatorias encontradas según su función y de establecer si pueden considerarse marcadores de posicionamiento. Luego analizamos su ocurrencia en los diversos tipos de fragmentos incrustados en las conversaciones (e.g. anécdotas, textos de opinión, textos de información, segmentos de habla no estructurada) a fin de determinar si el uso de dichas preguntas puede contribuir a la caracterización del tipo de fragmento en el que se producen.

\section{MARCO TEÓRICO}

\subsection{EL POSICIONAMIENTO INTERSUBJETIVO}

Dentro de la Teoría de la Valoración (Martin 2000, Martin y Rose 2003), White (2003) propone un marco de análisis para los recursos lingüísticos del compromiso, es decir, los elementos que se utilizan para adoptar un determinado "posicionamiento intersubjetivo". Dichos recursos se han estudiado bajo los nombres de modalidad, polaridad, evidencialidad, atenuación, concesión, intensificación, atribución y consecuencialidad (consequenciality). (Palmer 1986, Chafe y Nichols 1986 entre otros autores). Basándose en la perspectiva dialógica de Bakhtin/Bolosinov, White propone que estos ítems, que son diferentes en el nivel léxico gramatical, pueden agruparse desde el punto de vista de la semántica del discurso, ya que todos proveen los medios para que los hablantes/escritores adopten un posicionamiento hacia los diferentes puntos de vista o posicionamientos sociales que el texto activa, y de este modo se posicionan con respecto a los otros sujetos sociales que los sostienen. Las categorías que ofrece atienden a las diferencias en el modo en que la voz textual se compromete con las voces alternativas y/o los puntos de vista a los que el texto hace referencia. Así, el autor sostiene que estos recursos pueden dividirse en dos grandes grupos: los que abren el espacio a alternativas dialógicas (recursos heteroglósicos) y los que lo cierran (recursos monoglósicos). Dentro de los heteroglósicos, distingue entre los que producen expansión o restricción dialógica.

Si bien White en su marco de análisis hace referencia a 'hablantes/escritores', sus análisis se basan mayoritariamente en textos escritos, principalmente en editoriales periodísticos. En esta situación comunicativa, el escritor diseña a su audiencia en consenso o disenso con las proposiciones que el texto activa, pero no existe la posibilidad inmediata de que su interlocutor exprese su acuerdo/desacuerdo. Esta situación se 
revierte en nuestro corpus, ya que trabajamos con conversaciones espontáneas. Esto plantea una situación comunicativa diferente, en la cual entra en juego, además de la evaluación que hace el hablante acerca del mundo compartido con su audiencia -es decir, que 'diseñe' a su audiencia en consenso o disenso-, la devolución en tiempo real que provee el interlocutor en la co-construcción de la interacción.

\subsection{LAS PARTÍCULAS ¿NO? Y ¿SÍ? EN LA CONVERSACIÓN}

Ortega Olivares (1985) incluye a ¿no? y ¿ sí? entre los que denomina 'apéndices modalizadores comprobativos', junto con ¿verdad?, ¿de acuerdo?, ¿miento?, ¿no cree?, ¿vale? entre otros. Manifiesta que para un total discernimiento de su funcionamiento se necesitan presupuestos de índole pragmática (1985: 242) y no meras descripciones, ya que estos apéndices son recursos de interacción social.

Con respecto al ¿no?, explica que el hablante hace uso de este elemento cuando siente inseguridad acerca de lo que dice, o no quiere asumir totalmente el compromiso con el oyente. Es decir, en situaciones en las que también podría optarse por enunciados interrogativos, dubitativos o de posibilidad. Sin embargo, la selección de una u otra estructura conlleva significados diferentes. En el caso de ¿no? a continuación a una aserción, el hablante parece prever el contenido de la respuesta. Ortega Olivares cree posible afirmar que cuando el elemento ¿no? se utiliza para modalizar un enunciado base asertivo, el hablante intenta crear la obligación de contestar, y espera que la respuesta del oyente ratifique algo que ya suponía.

Para este autor, ¿sí? funciona de manera idéntica a ¿no?, aunque su frecuencia de ocurrencia es sustancialmente menor. Sostiene que no existen razones lingüísticas para que su uso sea diferente, y atribuye la diferencia a cuestiones de 'moda'.

García Vizcaíno (2005) realiza un estudio del uso de ¿no? y ¿eh? bajo la misma denominación de 'apéndices modalizadores'. Entiende que estos elementos influyen en la modalidad del enunciado (tanto epistémica como deóntica) ya que afectan el modo en que el emisor expresa o representa una acción, es decir, contribuyen a marcar la actitud del hablante hacia ese enunciado. Partiendo de lo postulado por Ortega Olivares, agrega que el funcionamiento de estas partículas no es únicamente 'comprobar' la corroboración del interlocutor, e identifica cuatro fuciones: comprobativa de pregunta, comprobativa de opinión, fática y expletiva.

Briz (2001) clasifica a ¿no? como un conector metadiscursivo de control de contacto, ya que "su función principal está orientada al control de los papeles comunicativos y de contacto entre los participantes de la enunciación y de éstos con el mensaje". (2001: 207). Distingue una función expresivo-fática, como fórmulas de reafirmación, y también observa una función apelativa que involucra al oyente. Por su parte, Gille, J. (2006a) incluye al ¿no? entre los 'apéndices de intersubjetividad'. Divide a estos apéndices en dos grandes grupos: los comprobativos, que regulan la interacción, la comprensión y la atención entre los participantes (no, eh, verdad, sabes, entiendes), y los interpersonales, que regulan el contacto y la relación entre los interlocutores (macho, tío, hombre, nano). Incluye en este grupo al apéndice vamos, que invita al interlocutor a colaborar en la interacción .

En inglés existe una construcción equivalente, las denominadas 'tag questions' (que podríamos traducir como 'apéndices interrogativos'). Estos 'apéndices' contienen una forma auxiliar de polaridad opuesta a la de la cláusula principal, y un pronombre que 
concuerda con el sujeto de la cláusula principal (the weather is awful, isn't it? O: Your friends couldn't come next week, could they?). En ambos ejemplos la polaridad de la cláusula principal se invierte en el apéndice: a la cláusula principal positiva corresponde un apéndice negativo, y a la cláusula negativa corresponde un apéndice positivo. Los apéndices de polaridad positiva también pueden aparecer junto a cláusulas positivas, pero su función es ligeramente diferente de los de polaridad inversa.

Entre la vasta bibliografía sobre el tema, podemos citar a Cameron et al. 1989; Holmes 1984b; Holmes 1995. Cameron sostiene que muchas 'tags' expresan tanto el significado afectivo como el referencial, y que no siempre es fácil asignarles la función primaria. Por lo tanto, es necesario atender cuidadosamente al contexto.

Por su parte, Holmes (1995) distingue cuatro tipos de tags:

1. Modal epistémica: Expresa la incertidumbre del hablante. Su función primaria es referencial más que afectiva. Se centra en la exactitud de la información expresada por la proposición y no en los sentimientos del destinatario.

2. Desafiante: Constituye una estrategia de confrontación. Puede utilizarse para presionar a un interlocutor reticente a responder o para intensificar agresivamente la fuerza de un acto de habla. Este tipo de tags se analizan como intensificadores (Se producen, por ejemplo, en las repreguntas en un juicio, por medio de las cuales se intenta destruir la credibilidad del testigo).

3. Facilitativa: Estas tags tienen una función atenuadora. Se utilizan como una estrategia de cortesía positiva. Invitan al destinatario a contribuir al discurso. Indican preocupación por las necesidades de los otros.

4. Atenuadora. Constituyen una estrategia de cortesía negativa, que se utiliza para atenuar la fuerza de emisiones con una carga afectiva negativa, como por ejemplo órdenes y críticas.

A partir de las consideraciones anteriores, puede observarse que existe coincidencia entre los distintos autores acerca de la función interpersonal de los elementos estudiados, y de la necesidad de atender cuidadosamente al contexto a fin de determinar su función pragmática en la interacción.

En nuestro estudio preferimos utilizar el término 'pregunta confirmatoria' y no 'apéndice', ya que por la función que cumplen como marcadores de posicionamiento pueden agruparse con otras preguntas que piden confirmación, por ejemplo ¿qué te parece? o ¿no es así?

\section{Resultados y Discusión}

Entendemos por 'Pregunta confirmatoria' aquella pregunta destinada a corroborar información u opinión, ya sea producida por el hablante acerca de su propia contribución

(1)

Ge: Pero la técnica, como base, creo que es fundamental. Pero, como una herramienta, no como... porque el problema después está en caer en la, en lo que es puramente técnico y, y... o sea, que falta la, la, la, la expresión... 
O producida por el interlocutor para confirmar si oyó/entendió bien:

(2)

Ge: Y que, viste por ahí no son negras... son de colores. [Algunas...]

Ce: [¡Ahh! ¿Sí?]

06EIIH8

El análisis del corpus permitió detectar la presencia de tres tipos de preguntas confirmatorias:

a) las que piden confirmación de 'hechos', y por lo tanto se relacionan con el nivel de certeza que tiene el hablante acerca de la proposición emitida.

(3)

Ma: $(\ldots)_{¿}$ Hablaste algo más con Manuela? ¿Te dijo si vio el examen o algo? No. ¿No?

Ro: No me contestó.

b) las que piden confirmación de evaluación/opinión.

06EIIM/H14

(4)

Ge: Pero la técnica, como base, creo que es fundamental. Pero, como una herramienta, no como...porque el problema después está en caer en la, en lo que es puramente técnico y, y... o sea, que falta la, la, la, la expresión... artística, ¿no?

06EIIH8

c) las que piden confirmación de comprensión, y cumplen, según Briz (2000), una función expresivo-fática. Este autor las considera fórmulas de reafirmación y sostiene que normalmente aparecen en posición interior de enunciado. Este tipo de preguntas ocurren en nuestro corpus exclusivamente en segmentos explicativos que no presentan evaluaciones, y podríamos parafrasearlas como ¿me seguís? o ¿me entendés? En estos casos las preguntas no son indicadoras de posicionamiento.

(5)

Tengo que dibujarlo en AutoCad. O sea, y.. ehh.. el profesor lo que nos da es lo que se llama el arreglo general, ¿sí? Ehh que es más o menos un, una vista, ehh, de perfil, en planta, de todas las cubiertas, ¿no? Y vos con eso sacás algunas medidas, después te da

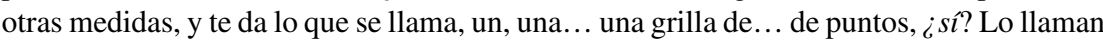
el, el cuadro de puntos.

06EIIIH 21

En este trabajo nos ocuparemos de las preguntas producidas por el hablante acerca de su propia contribución que piden confirmación de evaluación/opinión, ya que entendemos que son las que contribuyen a construir la prosodia del posicionamiento.

En el corpus analizado, las preguntas estudiadas se utilizan con las siguientes funciones:

\section{A. Proyectar acuerdo}

a) ¿No?

Las preguntas cuya función es proyectar acuerdo con el interlocutor se producen generalmente en medio de una contribución. El hablante emite una opinión y produce la pregunta, ¿no? pidiendo confirmación, pero no espera respuesta e inmediatamente 
reformula o amplía la opinión. Diseña a su interlocutor en consenso, asume un mundo compartido en el que el receptor está de acuerdo. La reformulación refuerza la opinión emitida en primer lugar y restringe la posibilidad de que el interlocutor manifieste una opinión contraria, ya que disentir implicaría un alto costo interpersonal. La pregunta, por lo tanto, puede clasificarse como un recurso heteroglósico de restricción dialógica ya que, si bien admite que puedan existir alternativas a lo expresado por el hablante, las posibilidades que tiene el interlocutor de presentar un punto de vista alternativo se ven limitadas. Esto puede apreciarse en el siguiente fragmento de un texto de opinión:

(6)

$G e$ : O sea, en mi caso, viste, cuando yo estuve en el colegio, si no fuera por, por Dreizzen... y no más, o sea no... o sea no, no, no sabría usar las acuarelas, por ejemplo. Viste, y son cosas mínimas, saber cómo tensar la hoja; ehh, y ciertas ideas de cómo conviene, empezar a, digamos, a pintar; eh, cómo manejar los colores. Y bueno, después, uno con la experimentación lo va ganando, ¿no? La práctica es fundamental.

Ce: Claro, pero... es como vos decís, pero si vos no, no sabés cómo... cómo tensar la hoja, no sabés cómo, cómo hacer las cap, las distintas capas de la acuarela, digamos que no... Ge: Claro.

06EIIH8

Gerardo emite su opinión, produce la pregunta ¿no?, y luego amplía opinión (1.6). La contribución de César (1.7) confirma el carácter restrictivo de la pregunta: no está de acuerdo, pero entiende que un desacuerdo frontal con una opinión presentada de esa forma amenazaría la imagen de Gerardo. Por lo tanto decide mitigar el desacuerdo emitiendo un acuerdo parcial.

Más adelante en la misma conversación encontramos un caso similar, pero que se resuelve de manera diferente:

$C e:$... no podés llegar, no, o sea, por más que, que vos después leés, un mont, tengas un mon, mucha práctica... vas a vavan, a evolucionar, pero te va a costar el triple.

$G e$ : Claro, sí, sí, sí. Y la, yo creo que la función del docente es que te vaya dando [elementos...]

Ce: [Claro.]

$G e: .$. para que vos... eh... puedas [crecer...]

$\mathrm{Ce}:[(\mathrm{Tose})]$

$G e:$... a partir de esos elementos, ¿no? puedas desarrollar tu práctica a partir de esos elementos que te da.

Ce: Mhm.

$G e:$ O una de las funciones del docente es esa... ehh...

Ce: Sí, a mí... (carraspea) .. Estehhh... .. Claro, de acuarela incluso tampoco vi mucho y... y si, o sea si no hay acuarela, o sea, tampoco vi... (tose) ...técnica de aerógrafo... [técnica...

06EIIH8

Germán comienza a expresar su opinión en la línea 4, y César lo alienta a seguir por medio de un elemento de retrocanalización en superposición (1.6 claro). Hasta este momento, César parece estar de acuerdo con Germán. Este continúa, hasta que 
produce la pregunta ¿no? y amplía o explica su opinión (1.9). Si bien Germán utiliza un recurso heteroglósico para presentar su punto de vista (1. 4 yo creo), la pregunta confirmatoria $i n o$ ? (1.9) tiene un efecto altamente restrictivo, como puede apreciarse por la reacción de César, quien solamente emite una retrocanalización como respuesta $(1.11 \mathrm{mmhm})$. Germán percibe el desacuerdo implícito, y reformula su opinión: en lugar de decir la función del docente, dice una de las funciones del docente, tratando de lograr consenso. César entonces intenta una respuesta, titubea y cambia de tema sin expresar el desacuerdo que parece latente.

También encontramos usos similares de la pregunta ¿no? en segmentos de habla no estructurada (Eggins y Slade 1997) (8) y en tramos narrativos (9).

(8)

MA: No, el otro día, no me acuerdo con quién hablábamos.. podés ir a una

fiesta que sea malísima y divertirte igual como.. lo contrario.

BE: Igual que cuando fuimos a.. cuál la fue de.. pará, un cumpleaños.. ah, el

de Mar.., el de.. [un compañero de la Facultad.]

MA: [El que nos colamos.] No, [el que nos colamos el año pasado.]

BE: [El que llegó y les dijo] "Ustedes son [las...]

MA: ["Las coladas"]

BE: [...las coladas"] que fuimos con Maru...

MA: En ese yo lo pasé re bien...

BE: Mhm

MA: ...y era chiquito, ¿no? No era ninguna gran fiesta.

BE: XXX colada.

(Risas)

BE: Te divertiste.

06EIIM25

Este fragmento es parte de un tramo de habla no estructurada en el que las participantes conversan acerca de algunas fiestas a las que han asistido. Malena emite su evaluación de una fiesta de cumpleaños, produce la pregunta confirmatoria y continúa con la reformulación que cierra su evaluación. De esta manera limita las posibilidades de disenso de Beatriz, quien presta acuerdo tácito, ya que finaliza con 'te divertiste', lo cual implica 'te divertiste a pesar de que no era una gran fiesta'.

(9)

La: [Un sábado, eh] Bueno, me sacan, me saca, me hace, pero, no sabés cómo me dolió, acá me sacó, ¿no? Me dolió, me quedó un moretón...

Ro: Es como una, una cosa, un mosquito que te pica.]

La: [Pará, pará]

06EIIH8

El segmento precedente ocurre en un texto narrativo acerca de una extracción de sangre. Larisa está refiriendo las vicisitudes que pasó cuando fue a extraerse sangre para hacerse un estudio. Al decir 'me dolió', Larisa efectúa una evaluación negativa de la enfermera que realizó la práctica. Luego de la pregunta confirmatoria, amplía la evaluación: no solamente le dolió, sino que le quedó un moretón.

En trabajos anteriores (Móccero 2007 y 2008) observamos que el posicionamiento adoptado por los hablantes puede propagarse a través de un fragmento genérico (Eggins 
y Slade 1997) conformando lo que llamamos una 'prosodia del posicionamiento'. La pregunta ¿no? en medio de una contribución puede actuar como un elemento 'bisagra' que marca la transición de posicionamiento monoglósico a heteroglósico, o viceversa. Esto puede apreciarse en el texto (10), en el cual Germán expresa su opinión acerca de la creatividad en los niños y en los adultos. El hablante comienza su contribución utilizando marcadores de posicionamiento heteroglósico: no sé, yo veo (1.1). Luego titubea e introduce la reformulación de una idea que no terminó de expresar utilizando recursos monoglósicos (afirmaciones categóricas 1.2-5). Coloca a su interlocutor dentro del mundo compartido al proyectar acuerdo por medio de 'viste que', con lo cual restringe las posibilidades de disenso (recurso monoglósico). Entendemos que el ¿no? que produce en medio de su contribución (pregunta confirmatoria retórica), por ser un recurso heteroglósico, pero de restricción dialógica, se encuentra articulando el paso de lo monoglósico a lo heteroglósico. Marca la transición hacia los recursos de expansión dialógica con los que Germán finaliza su contribución (elicitación de opinión, ¿qué te parece?).

Ge: [Y que,] que... no sé, yo veo que hay una cuestión de... de... o sea, hay un mo, una cuestión de que el chico, cuando uno es chico hay un máximo de creatividad, en general, que se va perdiendo... se va perdiendo... a lo largo de, de la vida. Se va perdiendo porque vamos adoptando lo que sería el comportamiento de un adulto, tradicional, digamos. No, no digo que se va perdiendo, lo, lo veo como una generalidad. Viste que hay, desde el adulto, hay un rechazo hacia lo que es la fantasía o la, o la... o sea, como que lo ven "algo como de chicos”, ¿no? Y yo asocio fan, fantasía con imaginación, con creación. Eh, Entonces eso es como ir cerrando, digamos, la, la, la personalidad. Yo no sé, creo, alguien que, que crea... alguien que hace arte lleva arte de creatividad en sí mismo. O sea, tiene... no sé, ¿qué te parece?

06EIIH8

b) ¿Sí?

Acordamos con Ortega Olivares en que la ocurrencia de ¿sí? es mucho menor la de de ¿no?, y que su uso parece estar relacionado con el estilo del hablante. En nuestro corpus, generalmente se produce en segmentos explicativos, es decir, cuando se explica algún proceso o procedimiento, y puede parafrasearse como ¿Me entendés? ¿Me explico? En dichos casos no marca posicionamiento, ya que no se describe una actitud. En las escasas ocurrencias encontradas en nuestra muestra en las que la pregunta ¿sí? aparece después de una evaluación, como en el fragmento que citamos a continuación,

Ma: La facultad está mal pensada ¿sí? Salvo algunos colegios universitarios y aún los universitarios no te dejan bien preparado para la facultad. Ahora, en contenidos, no... en contenidos aprendés todo, todas las materias empiezan de cero. ¿En qué no te dejan preparado entonces? Muy buena pregunta 
se utiliza, al igual que el ¿no?, para proyectar acuerdo con el interlocutor. Sin embargo, entendemos que la fuerza retórica de la pregunta ¿sí? es mayor que la de ¿no?, y que esto tiene que ver con la polaridad de los ítems empleados. Mientras que ¿sí? puede parafrasearse como 'asumo que estás de acuerdo', ¿no? puede parafrasearse como 'estás de acuerdo, ¿verdad? En el primer caso, y teniendo en cuenta el manejo de las relaciones sociales en la conversación, se le cierra prácticamente al receptor la posibilidad de sostener un punto de vista diferente, ya que hacerlo significaría una amenaza a la imagen de su interlocutor. En el segundo caso, la pregunta admite la posibilidad de disenso, pero la estructura de la conversación la cierra: el hablante continúa su contribución sin ceder el turno.

En el ejemplo (11), la pregunta $\Varangle s i ́$ ? parece estar destinada a reforzar la afirmación categórica anterior, y por lo tanto entendemos que su uso puede asimilarse al de un recurso monoglósico enfático (Móccero 2007a).

\section{B. Pedir opinión}

También es frecuente encontrar preguntas confirmatorias al final de una contribución en la que se emite una evaluación. En estos casos, generalmente el hablante cede el turno para que el interlocutor emita su propia opinión. Este recurso puede clasificarse como heteroglósico, de expansión dialógica, ya que, al requerir que el receptor manifieste acuerdo o desacuerdo con lo que acaba de escuchar, deja en claro que el hablante considera que existen alternativas a lo expresado. En el tramo que sigue, Germán emite su opinión acerca de lo que debería enseñarse en el Bachillerato de Bellas Artes, de donde ambos participantes son ex alumnos. Utiliza recursos heteroglósicos (yo creo, a mí, creo, para finalizar con el pedido de confirmación de opinión ¿no?). Sin embargo, las selecciones léxicas que emplea evidencian un alto grado de convencimiento acerca de lo que dice (fundamentalmente, fundamental). El receptor acepta la posibilidad de disentir que se le ofrece, pero minimiza la fricción que provocaría un desacuerdo no mitigado al comenzar su contribución con un acuerdo concesivo (Sí, lo que pasa..). (Móccero 2007)

$G e$. (...)Yo creo que lo que falta, fundamentalmente, es el desarrollo de la técnica que después te permite, a mí, crecer en la ex, en la expresión, o sea, en la expresión artística. Pero la técnica, como base, creo que es fundamental. Pero, como una herramienta, no como... porque el problema después está en caer en la, en lo que es puramente técnico y, y... o sea, que falta la, la, la, la expresión... artística, ¿no?

$C e$ : Sí, lo que pasa es que eso es, relativo. Lo de la expresión artística.

06EIIM/H14

Un uso similar encontramos en un segmento de Habla no estructurada, donde el ¿no? ocurre al final del turno, y pide opinión acerca de la evaluación enunciada.

H1: (Risas) Era porque me acordaba que, que querías ir temprano así estudiabas.

BE: No, no, así volvía temprano.

H1: Bueno, así volvías a estu..., temprano ¿para qué? para estudiar.

BE: No, para no XXX. 
H1: Ah, entonces para eso salís con Miguel.

BE: ¿La vuelta fija?

H1: La de la vuelta. Parece media mala ¿no?

BE: No, no sé, por ahí está buena.

Puede ocurrir que el hablante demuestre un cierto grado de inseguridad acerca de la opinión que emite. Diego (estudiante de Filosofía) e Ignacio (estudiante de Letras) están hablando sobre literatura.

(14)

Di: No es raro tampoco que las novelas terminen, como las películas, terminen peor de lo que...

Ig: Sí.

Di: ...se desarrollan. Quizá por, aparte porque... un poco por ahí, no tendrían que, ponele, terminar algunas novelas y el hecho de que tengan que terminar es lo que... ¿no?

Ig: Eh..

Di: Que sería... no sé si Agamben tiene, tiene una tesis así.

Ig: Vos me habías hablado de algo del fin del poema.

Di: Porque bueno, justamente, o sea, ésa sería la otra contracara del

carácter escatológico, digamos, o mesiánico del poema.

Ig: Sí.

06EIIM/H14

Diego produce una evaluación, pero introduce su justificación con varios elementos indicadores de posicionamiento heteroglósico (quizá, por ahí). Aún antes de finalizar, y sin llegar a un punto de transición, cede el turno y pide a Ignacio que confirme su opinión. Entendemos que, en este caso, la pregunta ¿no? es un recurso de expansión dialógica, ya que el hablante pide la opinión de su interlocutor. Sin embargo, observamos que Ignacio tampoco tiene una opinión formada al respecto, ya que no emite una opinión alternativa, sino que sus contribuciones se limitan a acuerdos monosilábicos y retrocanalizaciones.

\section{Conclusiones}

Las preguntas confirmatorias ¿no? y ¿sí? que se encuentran en fragmentos que expresan actitudes son indicadoras de posicionamiento intersubjetivo. El hecho mismo de que se formule la pregunta activa posturas alternativas a la expresada por el hablante (posicionamiento heteroglósico). Sin embargo, creemos que las preguntas estudiadas no poseen una fuerza retórica intrínseca, sino que ésta varía según el contexto en el que se producen. Encontramos que existen diferentes grados de expansión/restricción dialógica que pueden asociarse a la función de la pregunta en el contexto comunicativo en cuestión. El mayor grado de restricción opera en algunas preguntas retóricas utilizadas para proyectar acuerdo, ya que no sólo se asume un mundo compartido en el que los participantes piensan lo mismo, sino que el hablante continúa con su contribución sin ceder el turno, y por lo tanto cierra la posibilidad de 
que el interlocutor pueda acordar o disentir, salvo por medio de retrocanalizaciones o mecanismos no verbales. En la conversación cara-a-cara, el efecto producido por el posicionamiento adoptado por el hablante se pone de manifiesto en la respuesta del receptor. Así, cuando el hablante adopta un posicionamiento heteroglósico de expansión dialógica, su interlocutor generalmente responde expresando su propia opinión, a veces modalizada para no deteriorar la imagen social del primero.

Cuando el hablante emplea recursos altamente restrictivos, el receptor suele responder con retrocanalizaciones y cambios de tema para evitar la confrontación. Entendemos que los elementos heteroglósicos de restricción dialógica pueden tener una mayor o menor fuerza retórica según el propósito comunicativo del hablante, y que en algunos casos el efecto de la restricción dialógica puede llegar a ser equivalente al de la monoglosia. Es decir, puede llegar a anular las posibilidades de disentir del interlocutor. Así, el límite entre 'restricción dialógica' y 'monoglosia' puede llegar a desdibujarse.

En el presente estudio hemos analizado diferentes tipos de fragmentos incrustados en las conversaciones: narrativos, de opinión, explicativos, y también segmentos de habla no estructurada. Encontramos que, si bien las preguntas estudiadas se producen en todos los tipos analizados a excepción de los fragmentos explicativos, su mayor grado de ocurrencia se da en los segmentos de opinión, seguidos por los segmentos narrativos. Creemos que esto es así porque en dichos textos abundan las expresiones evaluativas, que denotan actitudes que posibilitan o requieren una toma de posicionamiento.

\section{OBRAS CITADAS}

Briz, A. 2001. El español coloquial en la conversación: esbozo de pragmagramática. Barcelona: Ariel.

Chafe, W. y J. Nichols. 1986. Evidentiality: The linguistic Coding of Epistemology, Norwod, NJ: Ablex .

García Vizcaíno, M. J. 2005. 'El uso de los apéndices Modalizadores ¿̨no? y ¿eh? en español peninsular. En: Selected Proceedings of the Second Workshop on Spanish Sociolinguistics, e. Lofti Sayahi y Maurice Westmoreland, 89-101.

Eggins, S. y D. Slade. 1997. Analysing Casual Conversation. London and Washington: Cassell.

Gille, J. 2006a. "Este hombre se debe mover, vamos. Un primer acercamiento a los apéndices conversacionales". En: Actas del XVI Congreso de Romanistas Escandinavos. CD-Rom.

Martin, J. y D. Rose. 2003. Working with Discourse. London: Continuum.

Martin, J. y P. White. 2005. The language of evaluation. Appraisal in English. New York: Palgrave.

Móccero, M.L. 2005. "El posicionamiento intersubjetivo en conversaciones informales". En: Actas del II Coloquio Argentino de la IADA. La Plata, 11-13 de mayo.

Móccero, M.L. 2007. "Opinión y posicionamiento". En: Actas del III Coloquio Argentino de la IADA. Plata, 28 al 30 de mayo de 2007.

Móccero, M.L. 2008. "Posicionamiento heteroglósico y prosodia en textos de opinión". Actas del I Congreso Internacional de Sociolingüística y Lingüística Histórica.Universidad Nacional del Sur. Universidad de Tucumán. Universidad de la República (Uruguay). 
Ortega Olivares, J. 1985. Apéndices modalizadores en español: los 'comprobativos'en: Estudios románicos dedicados al profesor Andrés Soria Ortega, I. Granada: Universidad de Granada, pp. 239-255.

Palmer, F.R. 1986. Mood and Modality. UK: CUP.

White, P.R: R. 2003a. "Appraisal-The language of evaluation and stance". En: The Handbook of Pragmatics. Bulcaen, C: (ed.) Benjamins, Amsterdam.

White, P.R: R. 2003b. "Beyond modality and hedging”. En: Text 23 (2) pgs. 259-284.

White, P.R: R. 2003a. "Appraisal-The language of evaluation and stance". En: The Handbook of Pragmatics. Bulcaen, C: (ed.) Benjamins, Amsterdam. 